\title{
Maternal Perception of Child Weight Among Mexicans in California and Mexico
}

\author{
Lisa G. Rosas • Kim G. Harley • Sylvia Guendelman • \\ Lia CH Fernald $\cdot$ Fabiola Mejia $\cdot$ Brenda Eskenazi
}

Published online: 13 November 2009

(C) The Author(s) 2009. This article is published with open access at Springerlink.com

\begin{abstract}
The prevalence of childhood overweight is high in Mexican immigrant communities in the United States. Understanding mother's perceptions of child weight in immigrants' country of origin may help to understand this high prevalence. The goal of this study was to examine and compare mothers' perception of weight in Mexico (MX) and in an immigrant community in California (CA). We assessed perceptions of child weight using a pictorial scale with 314 mothers of 5-year-old children in MX and 60 mothers of 5 year-old-children in CA. We compared maternal reports with children's objectively measured weight. Using chi-square and Analysis of Variance, we investigated associations of maternal perception of and satisfaction with weight according to socio-demographic characteristics. Mothers were more likely to underestimate their children's weight in CA than in MX. On average, CA mothers wanted their children to be smaller than they currently were and mothers in MX wanted their children to be bigger than they currently were. This differed by weight
\end{abstract}

L. G. Rosas

University of California San Francisco, 3333 California St. Suite

365, San Francisco, CA 94118, USA

e-mail: rosas1@fcm.ucsf.edu; Igrosas@gmail.com

K. G. Harley · B. Eskenazi ( $₫)$

University of California Berkeley, 2150 Shattuck Ave. Suite

600, Berkeley, CA 94704, USA

e-mail: eskenazi@berkeley.edu

S. Guendelman · L. C. Fernald

University of California Berkeley, 50 University Hall, MC 7360,

Berkeley, CA 94720-7360, USA

F. Mejia

Instituto Nacional de Salud Publica, Universidad No. 655. Col.

Santa María Ahuacatitlán, Cerrada Los Pinos y Caminera,

Cuernavaca, Morelos 62100, Mexico status in CA with mothers of normal weight and at-risk-foroverweight children wanting them to be bigger and mothers of overweight children wanting them to be smaller. In order for programs to be effective, mothers must be able to recognize their children as overweight and want to address it. Because underestimation of weight and a desire for a larger size is common in this population, programs to address overweight may be more effective if they focus on alternative benefits of weight control strategies, such as healthy child development.

Keywords Childhood overweight - Mexican immigrants $\cdot$ Perception of weight status

\section{Introduction}

As of the most recent United States (US) National Health and Nutrition Survey (NHANES 2003-2004), an estimated $14 \%$ of children age $2-5$ years living in the US were classified as overweight [1]. Young children of Mexican descent in the US are more likely to be overweight than their non-Hispanic white or black peers [1]. Despite the high prevalence of childhood overweight in this group, research has shown that mothers frequently do not identify their children as overweight $[2,3]$. Interventions to treat and prevent childhood overweight are unlikely to be successful if parents do not recognize children as overweight [4].

Mexican immigrant mothers may not identify their overweight children as such for several reasons. Qualitative research with Latina mothers has shown that mothers avoid labeling their children as "overweight" [5]. Misperception may also be related to shifting weight norms in Mexican immigrant communities due to significant increases in the 
prevalence of overweight $[1,6]$. Cultural norms regarding the ideal weight for young children could also affect measures of misperception. For example, parents of young Mexican-American children may prefer a larger body type compared to a smaller body type and thus may not identify them as overweight [7]. This desire for a heavier child may have its roots in the communities of origin in Mexico. An anthropologic investigation of childhood obesity in Mexico revealed that parents perceived "chubby children as healthy children" [8].

Although several studies have addressed misperception of weight status in this population, few have sought to compare perception of weight status between migrants living in the US and those living in Mexico. Understanding the level of misperception as well as mothers' perception of ideal weight in both Mexican immigrant communities in the US as well as communities of origin in Mexico could inform interventions for this binational population. Therefore, the goal of this study was to examine the relationship of child's actual weight with mothers' perception of children's current weight as well as ideal weight in a Mexican immigrant community in California and migrant sending communities in Mexico.

\section{Methods}

\section{Study Design and Participants}

We chose to conduct this study with mothers of 5-year-old children because the adiposity rebound, which is known to occur between 5 and 7 years of age, is a critical period for development of adolescent and adult adiposity [9-11]. We used data from a binational study of 5-year-old children and their mothers residing in migrant communities in California and Mexico, which was comprised of two cross-sectional samples. The children from California (CA) were participants of the Center for the Health Assessment of Mothers and Children of Salinas (CHAMACOS) study, a longitudinal birth cohort of pregnant women and their children living in the agricultural region of Salinas Valley, California. The CHAMACOS study has been described elsewhere [12]. Briefly, pregnant women were recruited from 1999 to 2000 in 6 prenatal clinics that serve a predominantly low-income, Spanish-speaking population. Eligible women were 18 years or older, less than 20 weeks gestation at enrollment, English- or Spanish-speaking, Medi-Cal eligible and planned to deliver at the county hospital. For the present study, the CA sample was restricted to a sub-sample of Mexican-born women and their children who completed a supplemental questionnaire on weight perception when the children were 5 years-old. Of the 305 follow-up interviews conducted with Mexican-born mothers and their 5-year-old children, 60 women answered the supplemental questionnaire, which was administered from March 2006 to August 2006. There were no significant differences between the 60 mother-child pairs who completed the supplemental questionnaire and the 245 women who did not according to child sex, child weight status, maternal weight status, maternal education, marital status, poverty level, household food insecurity, receiving food assistance or mother's length of residence in the US.

The Mexican (MX) sample was designed to capture a group of women and their children living in Mexico who closely resembled the CA sample, yet who never migrated to the US. In CA, Mexican-born women were most commonly from the states of Guanajuato (20\%), Jalisco (12\%) and Michoacán (24\%). Thus, the MX sample included women and their 5-year-old children from high-migration communities in Guanajuato, Jalisco and Michoacán. We defined municipalities as high-migration if $10 \%$ or more of the male population resided in the US in at least $40-50 \%$ of the towns or districts within the municipality, as of the most recent Mexican census in 2005 [13]. The high-migration municipalities of Irapuato and Celaya in Guanajuato; Uruapan and Apatzingan in Michoacán; and Tlaquepaque and Zapopan in Jalisco were selected. Women and their 5-year-old children were recruited from June 2006 to August 2006 through the federal conditional cash transfer program, Oportunidades, which provides health care services and nutrition supplementation to vulnerable groups (young children, pregnant and lactating women) in addition to monetary benefits conditional on families' participation in education and preventive services. In MX, women and their 5-year-old children were eligible to participate if the child was approximately 5 years old (59-66 months), the mother and child were currently receiving the Oportunidades benefits; the mother and child lived exclusively in Mexico and had never migrated to the US for longer than 1 month, and the mother spoke fluent Spanish. Questions on perceptions of child weight were asked of all MX participants. Of the original 317 mother-child pairs, we excluded those with missing anthropometric information $(n=1)$, implausible anthropometric information $(n=1)$ or missing information on perceived weight $(n=1)$ for a final sample size of 314 .

All protocols, study instruments and consent forms were reviewed and approved by the Institutional Review Boards at the University of California, Berkeley and at the National Institute of Public Health in Mexico. Informed consent was obtained from all participants.

\section{Procedures}

Children were weighed and measured by trained staff without jackets and shoes using a calibrated electronic 
Tanita scale (Tanita Mother-Baby Scale Model 1582, Tanita Corp.) and stadiometers. We calculated body mass index (BMI) as mass in kilograms divided by height in meters squared and compared these values with sex-specific BMI-for-age percentile data issued by the Centers for Disease Control and Prevention (CDC) in 2000 [14]. We classified children who were at or above the 85 th percentile but less than the 95th percentile as "at risk for overweight" and those at or above the 95th percentile as "overweight" [14].

To assess mothers' perceptions of their children's weight, mothers were presented a scale comprised of seven figures, which was developed by Collins [15] (see Fig. 1). Mothers were first asked to select the figure they perceived best corresponded to their child's current appearance and then the figure that best corresponded to an "ideal" appearance. Similar figure scales have been used in other studies on weight perception in the US with Hispanic and Mexican immigrant populations [7, 16, 17] and in one study in Mexico [18].

Mother's height and weight were measured with shoes and coats removed using an electronic Tanita scale (Tanita Mother-Baby Scale Model 1582, Tanita Corp.) and a stadiometer. Mother's weight status was defined as overweight if her BMI was greater than or equal to 25 and less than 30 and obese if her BMI was 30 or greater [19]. Differing measures of socioeconomic status (SES) were used in CA and MX. In Mexico, a developing country where income measures do not accurately characterize SES [20], a summary measure of housing characteristics and household assets served as a proxy measure. Summary measures of housing characteristics and assets have been shown to be effective in ranking and capturing a family's longer-term SES levels, which are ideal for studies of health outcomes [20] and have also been used in nationally representative surveys in Mexico such as the National Social Welfare Survey [21]. We used a principal component analysis to summarize housing characteristics and assets and the first principal component weightings were retained [22]; a weighted score was calculated for each woman, and the weighted scores were divided into tertiles. In CA, SES was measured using a continuous measure of per capita household income divided into tertiles.

Maternal education was categorized as elementary school or less (less than 6th grade), middle or high school (less than 12th grade) or, high school graduate or more (12th grade or more) based on mother's account of the level of school she completed in either Mexico or the US. Mother's length of residence in the US was used as a proxy for acculturation in the CA sample given that all women were foreign-born and the majority was monolingual Spanish-speaking [23]. In MX, women were asked if the child's father or the current head of household or any other close family member (grandparents, parents, siblings or other children) had migrated to the US for work and if any of them were currently residing in the US.
Fig. 1 Mother's selection of Collins scale figures in California (Salinas, CA) and Mexico (Guanajuato, Jalisco, Michoacán)
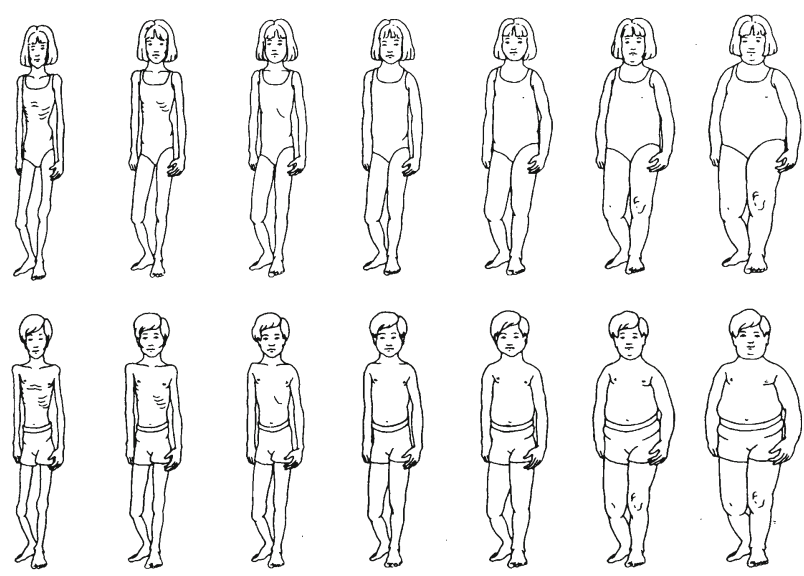

\begin{tabular}{|c|c|c|c|c|c|c|c|}
\hline Collins scale figure \# & 1 & 2 & 3 & 4 & 5 & 6 & 7 \\
\hline \multirow[t]{3}{*}{ Converted Z-score } & -3 & -2 & -1 & 0 & 1 & 2 & 3 \\
\hline & \multicolumn{2}{|c|}{ Underweight } & \multicolumn{3}{|c|}{ Normal weight } & $\begin{array}{l}\text { At risk for } \\
\text { overweight }\end{array}$ & Overweight \\
\hline & $\mathrm{n}(\%)$ & $\mathrm{n}(\%)$ & $\mathrm{n}(\%)$ & $\mathrm{n}(\%)$ & $\mathrm{n} \quad(\%)$ & $\mathrm{n}(\%)$ & $\mathrm{n}(\%)$ \\
\hline \multicolumn{8}{|l|}{ California, $n=60$} \\
\hline Current & $1(2)$ & $9(15)$ & $17(28)$ & $14(23)$ & $13(22)$ & $6(10)$ & \\
\hline Ideal & & $3(5)$ & $19(32)$ & $29(48)$ & $9(15)$ & & \\
\hline \multicolumn{8}{|l|}{ Mexico, $n=314$} \\
\hline Current & $1(3)$ & $39(12)$ & $78(25)$ & $131(42)$ & $50(16)$ & $8(3)$ & \\
\hline Ideal & & $7(2)$ & $37(12)$ & $186(59)$ & $81(26)$ & $3(1)$ & \\
\hline
\end{tabular}




\section{Statistical Analysis}

To compare children's actual weight to the mothers' perception of their child's current and ideal weight, we calculated standardized $z$-scores. For the objective weight measurement, we used BMI $z$-scores obtained from comparing children's BMI to the CDC sex-specific BMIfor-age percentile data [14]. For the perceived and ideal weight, we standardized the Collins figure scale as described by Maximova et al. so that each figure was assigned a corresponding $z$-score with the middle figure (Collins Fig. 4) as the mean with a $z$-score of 0 [24]. Because the figures are highly correlated with objectively measured BMI percentiles [25, 26], $z$-scores of $-1,0$ and 1 represent normal weight, a $z$-score of 2 represents at risk for overweight and a $z$-score of 3 represents overweight. Based on the standardized objective and subjective $z$-scores, we calculated two difference scores to describe the mother's perception of her child's weight status:

1. Perception score: the difference between the child's actual BMI $z$-score and the mother's perceived weight $z$-score based on the Collins figure scale. A negative value represents an underestimation of the child's true weight and a positive value represents an overestimation of the child's true weight.

2. Satisfaction score: the difference between the ideal weight $z$-score (based on mothers' indication of an ideal size on the Collins scale) and perceived weight $z$-score. The perceived satisfaction score indicates if the mother would like the child to be bigger (positive value) or smaller (negative value).

We compared perceived and ideal weight $z$-scores as well as the two difference scores from CA mothers with those of MX mothers using $t$-tests. Additionally, we assessed whether any of the continuous $z$-scores or difference scores significantly differed according to several demographic characteristics as well as child and maternal weight status using t-tests for dichotomous variables and Analysis of Variance (ANOVA) for categorical variables.

\section{Results}

As seen in Table 1, children from the CA sample were significantly $(p<0.01)$ more likely to be at risk for overweight (15 vs. $8 \%$ ) or overweight (42 vs. $7 \%$ ) compared to children from the MX sample, using the CDC criteria. However, the prevalence of maternal overweight and obesity was similar in CA and MX with 38 and 34\% classified as obese, respectively. Children from the CA sample were more likely to have a mother with a high
Table 1 Selected socio-demographic characteristics of participants from California (Salinas, CA) and Mexico (Guanajuato, Jalisco and Michoacán)

\begin{tabular}{|c|c|c|c|c|c|}
\hline \multirow[t]{3}{*}{ Characteristic } & \multirow{2}{*}{\multicolumn{2}{|c|}{$\frac{\text { California }}{n=60}$}} & \multirow{2}{*}{\multicolumn{2}{|c|}{$\begin{array}{l}\text { Mexico } \\
n=314\end{array}$}} & \multirow[t]{3}{*}{$p$-value ${ }^{\mathrm{a}}$} \\
\hline & & & & & \\
\hline & $n$ & $(\%)$ & $n$ & $(\%)$ & \\
\hline Sex & & & & & 0.73 \\
\hline Male & 27 & (45.0) & 149 & $(47.5)$ & \\
\hline Female & 33 & $(55.0)$ & 165 & $(52.6)$ & \\
\hline Child weight status & & & & & $<0.01$ \\
\hline Normal & 26 & $(43.3)$ & 267 & $(85.0)$ & \\
\hline At risk for overweight & 9 & $(15.0)$ & 26 & $(8.3)$ & \\
\hline Overweight & 25 & $(41.7)$ & 21 & $(6.7)$ & \\
\hline Mother weight status & & & & & 0.39 \\
\hline Normal & 10 & $(16.7)$ & 78 & $(24.8)$ & \\
\hline Overweight & 27 & $(45.0)$ & 130 & $(41.4)$ & \\
\hline Obese & 23 & $(38.3)$ & 106 & $(33.8)$ & \\
\hline Mother education level & & & & & $<0.01^{\dagger}$ \\
\hline Elementary or less & 26 & $(43.3)$ & 216 & $(68.8)$ & \\
\hline Middle or high school & 24 & $(40.0)$ & 92 & $(29.3)$ & \\
\hline High school graduate or more & 10 & $(16.7)$ & 6 & (1.9) & \\
\hline Marital Status & & & & & 0.18 \\
\hline Married/living as married & 53 & (88.3) & 293 & (93.3) & \\
\hline Not married & 7 & $(11.7)$ & 21 & $(6.7)$ & \\
\hline SES & & & & & 0.46 \\
\hline Low & 25 & $(41.7)$ & 105 & $(33.7)$ & \\
\hline Medium & 16 & $(26.7)$ & 102 & $(32.7)$ & \\
\hline High & 19 & $(31.7)$ & 105 & $(33.7)$ & \\
\hline Mother's years in the US & & & & & \\
\hline $5-10$ years & 25 & $(41.7)$ & & & \\
\hline $11-15$ years & 20 & $(33.3)$ & & & \\
\hline 16 years or more & 15 & $(25.0)$ & & & \\
\hline $\begin{array}{l}\text { Family member currently in the } \\
\text { US }\end{array}$ & & & & & \\
\hline No & & & 139 & $(44.3)$ & \\
\hline Yes & & & 175 & $(55.7)$ & \\
\hline
\end{tabular}

\footnotetext{
${ }^{\dagger}$ Fisher's Exact $p$-value

${ }^{\text {a }}$ Chi-square $p$-value unless indicated as a Fishers Exact $p$-value
}

school education or greater (16 vs. $2 \% p<0.01)$ than children from MX. Approximately $42 \%$ of mothers in the CA sample had lived in the US less than 10 years and over half $(56 \%)$ of the MX mothers reported that at least one of their family members currently lived in the US.

\section{Mothers' Perception of Current Child Weight}

Overall, CA mothers were less likely to choose a Collins scale figure close to their child's current objectively measured weight than MX mothers (see perception score Table 2, $p<0.01$ ). Although $57 \%$ of CA children were 
Table 2 Perceived weight $z$-scores and perception scores in California and Mexico

\begin{tabular}{|c|c|c|c|c|c|c|c|c|c|c|c|c|}
\hline & \multicolumn{6}{|c|}{ California $n=60$} & \multicolumn{6}{|c|}{ Mexico $n=314$} \\
\hline & \multicolumn{2}{|c|}{$\begin{array}{l}\text { Perceived } \\
\text { weight } z \text {-score }\end{array}$} & \multirow[t]{2}{*}{$p$-value ${ }^{\mathrm{b}}$} & \multicolumn{2}{|c|}{$\begin{array}{l}\text { Perception } \\
\text { score }^{\mathrm{c}}\end{array}$} & \multirow[t]{2}{*}{$p$-value ${ }^{\mathrm{b}}$} & \multicolumn{2}{|c|}{$\begin{array}{l}\text { Perceived } \\
\text { weight } z \text {-score }\end{array}$} & \multirow[t]{2}{*}{$p$-value $\mathrm{e}^{\mathrm{b}}$} & \multicolumn{2}{|c|}{$\begin{array}{l}\text { Perception } \\
\text { score }^{\mathrm{c}}\end{array}$} & \multirow[t]{2}{*}{$p$-value ${ }^{\mathrm{b}}$} \\
\hline & Mean & (SD) & & Mean & (SD) & & Mean & (SD) & & Mean & (SD) & \\
\hline Total & -0.2 & $(1.3)$ & & $-1.5^{\mathrm{d}}$ & $(0.8)$ & & -0.4 & $(1.1)$ & & $-0.4^{\mathrm{d}}$ & $(1.1)$ & \\
\hline Sex & & & 0.82 & & & 0.62 & & & 0.02 & & & 0.13 \\
\hline Male & -0.3 & $(1.2)$ & & -1.6 & $(0.8)$ & & -0.2 & $(1.0)$ & & -0.3 & $(1.0)$ & \\
\hline Female & -0.2 & (1.3) & & -1.5 & $(0.7)$ & & -0.5 & $(1.0)$ & & -0.5 & $(1.2)$ & \\
\hline Child weight status (CDC criteria) & & & $<0.01$ & & & 0.43 & & & $<0.01$ & & & $<0.01$ \\
\hline Normal & -1.2 & $(0.8)$ & & -1.4 & $(0.7)$ & & -0.5 & $(1.0)$ & & -0.3 & $(1.1)$ & \\
\hline At risk for overweight & -0.6 & $(1.0)$ & & -1.8 & $(1.0)$ & & 0.2 & $(0.9)$ & & -1.1 & $(0.8)$ & \\
\hline Overweight & 0.9 & $(0.9)$ & & -1.5 & $(0.8)$ & & 1.0 & $(1.1)$ & & -1.3 & $(1.0)$ & \\
\hline Mother weight status & & & 0.59 & & & 0.63 & & & 0.32 & & & 0.01 \\
\hline Normal & -0.4 & $(1.0)$ & & -1.4 & $(0.5)$ & & -0.4 & $(0.9)$ & & -0.1 & (1.1) & \\
\hline Overweight & -0.3 & (1.3) & & -1.4 & $(0.8)$ & & -0.5 & $(1.1)$ & & -0.5 & $(1.2)$ & \\
\hline Obese & 0.0 & (1.4) & & -1.6 & $(0.9)$ & & -0.2 & (1.1) & & -0.5 & $(1.0)$ & \\
\hline Mother education level & & & 0.23 & & & 0.15 & & & 0.75 & & & 0.83 \\
\hline Elementary or less & -0.3 & (1.3) & & -1.7 & $(0.8)$ & & -0.4 & (1.1) & & -0.4 & $(1.2)$ & \\
\hline Middle or high school & -0.4 & $(1.2)$ & & -1.3 & $(0.8)$ & & -0.3 & $(0.9)$ & & -0.4 & $(0.9)$ & \\
\hline High school graduate or more & 0.4 & (1.3) & & -1.3 & $(0.5)$ & & -0.3 & $(0.5)$ & & -0.2 & $(0.5)$ & \\
\hline SES & & & 0.42 & & & 0.78 & & & 0.18 & & & 0.57 \\
\hline Low & -0.2 & (1.4) & & -1.6 & $(0.9)$ & & -0.5 & (1.1) & & -0.3 & (1.1) & \\
\hline Medium & -0.6 & (1.0) & & -1.4 & $(0.7)$ & & -0.2 & (1.1) & & -0.4 & (1.1) & \\
\hline High & 0.0 & (1.3) & & -1.5 & $(0.7)$ & & -0.4 & $(0.9)$ & & -0.5 & (1.1) & \\
\hline Mother's years in the US & & & 0.73 & & & 0.80 & & & & & & \\
\hline $5-10$ years & -0.4 & (1.3) & & -1.4 & $(0.7)$ & & & & & & & \\
\hline $11-15$ years & -0.1 & $(1.2)$ & & -1.5 & $(0.6)$ & & & & & & & \\
\hline 16 years or more & -0.2 & (1.4) & & -1.6 & (1.1) & & & & & & & \\
\hline Family member currently in the US & & & & & & & & & 0.87 & & & 0.44 \\
\hline No & & & & & & & -0.4 & $(1.1)$ & & -0.5 & $(1.2)$ & \\
\hline Yes & & & & & & & -0.4 & $(1.0)$ & & -0.4 & $(1.0)$ & \\
\hline
\end{tabular}

${ }^{a}$ Perceived weight $z$-scores are standardized values derived from Collin's figure scale

b ANOVA $p$-values for variables with three categories and $t$-tests for variables with two categories

${ }^{c}$ Perception score represents the difference between the true BMI $z$-score and the perceived weight $z$-score; a negative value means an underestimation of the true weight and a positive value means an overestimation of the true weight

${ }^{\mathrm{d}} p<0.01$ for difference in perception score between California and Mexico

classified as at risk for overweight or overweight according to their objectively measured BMI, Fig. 1 shows that only $10 \%$ of CA mothers chose a figure on the Collins scale corresponding to those categories. The average difference in perceived and objective weight $z$-scores for CA children was -1.5 (perception score). Thus, on average, CA mothers underestimated their children's weight by approximately one and a half standard deviations. No child or maternal characteristics were associated with mother's perception of current body type (perceived weight $z$-score) or with the difference between her perception and the actual BMI (perception score) in CA with one exception. Mothers of overweight children perceived their children to be larger than mothers of normal weight children perceived their children to be $(p<0.01)$ (Table 2).

In contrast to the CA sample, $85 \%$ of children from the MX sample were classified as normal weight according to their BMI and $82 \%$ of mothers chose a figure corresponding to the normal weight category (Fig. 1). As seen in Table 2, the average perception score decreased significantly from -0.3 to -1.3 with increasing child weight status $(p<0.01)$, signifying that mothers underestimated their children's weight to a greater degree if the child was at risk for being overweight or overweight compared to normal weight. 


\section{Mothers' Perception of Ideal Child Weight}

Almost all mothers (97\%) from both samples chose ideal figures within one standard deviation of the mean (see Fig. 1), which corresponds to the normal weight category. However, as seen in Table 3, MX mothers chose a larger ideal body size than CA mothers, on average $(p<0.01)$.

CA mothers chose an ideal figure slightly below the mean on average $(-0.3)$, which was not significantly different than the mean perceived weight $z$-score of -0.2 $(p=0.77$, not shown). As a result, the satisfaction score, representing the difference between the ideal and perceived weight $z$-scores, was small at -0.1 . It appeared that CA mothers uniformly chose a similar ideal figure, with no significant differences according to any of the demographic characteristics (Table 3). In CA, the satisfaction score decreased significantly with increasing child weight status from 0.7 for normal weight children to -0.9 for overweight children $(p<0.01)$. This means that although mothers wanted their children to be smaller overall, mothers of normal weight children wanted them to be bigger and mothers of overweight children wanted them to be smaller. Mothers of children classified as at-risk-for-overweight in CA had a positive average satisfaction score, signifying

Table 3 Ideal weight $z$-scores, perceived and actual satisfaction scores for California and Mexico

\begin{tabular}{|c|c|c|c|c|c|c|c|c|c|c|c|c|}
\hline & \multicolumn{6}{|c|}{ California $n=60$} & \multicolumn{6}{|c|}{ Mexico $n=314$} \\
\hline & \multicolumn{2}{|c|}{$\begin{array}{l}\text { Ideal weight } \\
z \text {-score }\end{array}$} & \multirow[t]{2}{*}{$p$-value ${ }^{\mathrm{b}}$} & \multicolumn{2}{|c|}{$\begin{array}{l}\text { Satisfaction } \\
\text { score }^{c}\end{array}$} & \multirow[t]{2}{*}{$p$-value ${ }^{\mathrm{b}}$} & \multicolumn{2}{|c|}{$\begin{array}{l}\text { Ideal weight } \\
z \text {-score }\end{array}$} & \multirow[t]{2}{*}{$p$-value ${ }^{\mathrm{b}}$} & \multicolumn{2}{|c|}{$\begin{array}{l}\text { Satisfaction } \\
\text { score }^{c}\end{array}$} & \multirow[t]{2}{*}{$p$-value ${ }^{\mathrm{b}}$} \\
\hline & Mean & (SD) & & Mean & (SD) & & Mean & (SD) & & Mean & (SD) & \\
\hline Total & $-0.3^{\mathrm{d}}$ & $(0.8)$ & & -0.1 & (1.3) & & $0.1^{\mathrm{d}}$ & $(0.7)$ & & 0.5 & (1.1) & \\
\hline Sex & & & 0.69 & & & 0.64 & & & 0.05 & & & 0.29 \\
\hline Male & -0.2 & $(0.7)$ & & 0.0 & $(1.2)$ & & 0.2 & $(0.6)$ & & 0.4 & $(1.0)$ & \\
\hline Female & -0.3 & $(0.8)$ & & -0.1 & (1.4) & & 0.0 & $(0.7)$ & & 0.5 & $(1.2)$ & \\
\hline Child weight status (CDC criteria) & & & 0.10 & & & $<0.01$ & & & 0.17 & & & $<0.01$ \\
\hline Normal & -0.5 & $(0.6)$ & & 0.7 & $(1.0)$ & & 0.1 & $(0.7)$ & & 0.7 & $(1.0)$ & \\
\hline At risk for overweight & -0.2 & $(1.0)$ & & 0.3 & $(1.2)$ & & -0.1 & $(0.6)$ & & -0.3 & $(0.8)$ & \\
\hline Overweight & 0.0 & $(0.8)$ & & -0.9 & $(1.1)$ & & 0.0 & $(0.7)$ & & -1.1 & $(1.0)$ & \\
\hline Mother weight status & & & 0.83 & & & 0.60 & & & 0.01 & & & 0.05 \\
\hline Normal & -0.4 & $(0.8)$ & & 0.0 & $(0.7)$ & & 0.3 & $(0.7)$ & & 0.7 & $(1.0)$ & \\
\hline Overweight & -0.2 & $(0.8)$ & & 0.1 & (1.5) & & 0.0 & $(0.7)$ & & 0.5 & $(1.1)$ & \\
\hline Obese & -0.3 & $(0.7)$ & & -0.3 & (1.3) & & 0.1 & $(0.6)$ & & 0.3 & $(1.1)$ & \\
\hline Mother education level & & & 0.24 & & & 0.62 & & & 0.71 & & & 0.80 \\
\hline Elementary or less & -0.2 & $(0.9)$ & & 0.1 & (1.6) & & 0.1 & $(0.7)$ & & 0.5 & (1.2) & \\
\hline Middle or high school & -0.5 & $(0.7)$ & & 0.0 & $(1.0)$ & & 0.1 & $(0.6)$ & & 0.4 & $(0.9)$ & \\
\hline High school graduate or more & 0.0 & $(0.5)$ & & -0.4 & $(1.3)$ & & 0.3 & $(0.8)$ & & 0.7 & $(0.8)$ & \\
\hline SES & & & 0.26 & & & 0.08 & & & 0.99 & & & 0.21 \\
\hline Low & -0.4 & $(0.9)$ & & -0.2 & (1.4) & & 0.1 & $(0.8)$ & & 0.6 & $(1.2)$ & \\
\hline Medium & 0.0 & $(0.6)$ & & 0.6 & $(1.0)$ & & 0.1 & $(0.7)$ & & 0.3 & $(1.2)$ & \\
\hline High & -0.3 & $(0.7)$ & & -0.3 & $(1.3)$ & & 0.1 & $(0.6)$ & & 0.5 & $(1.0)$ & \\
\hline Mother's years in the US & & & 0.27 & & & 0.25 & & & & & & \\
\hline $5-10$ years & -0.1 & $(0.7)$ & & 0.3 & $(1.1)$ & & & & & & & \\
\hline $11-15$ years & -0.4 & $(0.9)$ & & -0.3 & $(1.4)$ & & & & & & & \\
\hline 16 years or more & -0.5 & $(0.6)$ & & -0.3 & (1.4) & & & & & & & \\
\hline Family member currently in the US & & & & & & & & & 0.15 & & & 0.44 \\
\hline No & & & & & & & 0.1 & $(0.8)$ & & 0.4 & (1.1) & \\
\hline Yes & & & & & & & 0.2 & (0.6) & & 0.5 & (1.1) & \\
\hline
\end{tabular}

${ }^{a}$ Ideal weight $z$-scores are standardized values derived from Collins figure scale

b ANOVA $p$-values for variables with three categories and $t$-tests for variables with two categories

${ }^{c}$ Satisfaction score represents the difference between the ideal weight $z$-score and the perceived weight $z$-score; a negative value means a mother wants a child to be smaller and a positive value means a mother wants a child to be bigger

${ }^{\mathrm{d}} p<0.01$ for difference in ideal weight $\mathrm{z}$-score between California and Mexico 
they wanted their children to be bigger than they thought they currently were (Table 3).

In contrast to the $\mathrm{CA}$ results, the average ideal figure was significantly larger than the average perceived figure in MX ( $p<0.01$, not shown). This means that MX mothers preferred their children to be larger than they currently were, on average. MX mothers chose a similar ideal silhouette for children of all weight status categories as seen in Table 3. However, mothers of males chose a slightly larger ideal size than mothers of females, (0.2 vs. 0.0 $p=0.05)$ and normal weight mothers $(0.3)$ chose a larger ideal silhouette than overweight $(0.0)$ and obese $(0.1)$ mothers $(p=0.01)$. Similar to CA, Table 3 shows that MX mothers of normal weight children wanted their children to be bigger (satisfaction score of 0.7) and wanted their overweight children to be smaller (satisfaction score of -1.1). However, in contrast with $\mathrm{CA}$, MX mothers of children at risk for overweight preferred for their children to be smaller with a satisfaction score of -0.3 .

\section{Discussion}

In this binational study we found that immigrant mothers in the US were more likely to underestimate their children's weight than mothers in Mexico and that, on average, mothers living in the US wanted their children to be smaller than they currently are and mothers in Mexico wanted their children to be bigger than they currently are. This study also generated hypotheses for how Mexico-US migration may impact maternal perception of child weight.

With all but one of the mothers from the California sample underestimating their child's weight, this study found a higher level of misperception than other studies of mothers of young children in the US. Other studies in the US have found that mothers' misperception of their overweight children's weight status ranged from $32 \%$ from an analysis of non-Hispanic white mothers in NHANES to $79 \%$ in a study of mothers attending either WIC or private clinics [27-31]. Studies focusing on Hispanic or MexicanAmerican mothers in the US have also found that maternal misperception of child weight status is prevalent $[2,3,7$, 17, 32]. For example, two studies that used similar silhouettes to the ones we used in our study, concluded that mothers generally chose a silhouette smaller than their child's actual size [7, 17]. A second set of studies that used a questionnaire to assess mothers' perception of their overweight children found that maternal misperception ranged from $36 \%$ in a study of Hispanic mothers in Virginia $(n=200)$ [32] to approximately $60 \%$ in both a study of 250 mothers of kindergarteners in primarily MexicanAmerican neighborhoods in Chicago [2] and a study of mostly Mexican-American WIC participants in Nevada
( $n=38)$ [3]. Approximately half as many mothers underestimated their child's weight in the Mexico sample compared to California. The level of misperception is likely lower in Mexico compared to California because of the high prevalence of childhood overweight in the US sample.

Misperception may have been higher in our study because of difficulties with the Collins scale. We used the pictorial scale to assess mother's perception of child weight status as opposed to asking mothers to report their child's weight status as has been done in other studies because research has found that mothers, especially Latinas, avoid labeling their children as overweight [5]. Therefore the silhouettes offered a method to avoid the label of overweight. However, mothers may have had a difficult time finding a silhouette that looked like their child.

The majority $(96 \%)$ of mothers in both samples chose ideal figures within the range corresponding to normal weight (Collins Figs. 3, 4 and 5), although we documented a significantly higher ideal weight preference in Mexico compared to California. In Mexico, the notion that "chubby children are healthy children," has been reported to be a commonly held belief [33]. In fact, when mothers in Mexico were asked why they chose the ideal figure, the majority of women said it looked healthier (data not shown). A preference for a larger ideal child weight in Mexico may be a response to the realities of children's nutritional status in Mexico. Mexico is a developing country that still experiences significant undernutrition [34]. Additionally, three-quarters of the Mexican sample reported household food insecurity, which was only reported in approximately $40 \%$ of the California households [35]. Thus, Mexican mothers may also prefer a larger ideal child weight in response to limited nutritional resources.

This study generated hypotheses for how maternal perception of the ideal child weight may be influenced by migration. First, we found that Mexican immigrant mothers preferred a smaller ideal body type on average compared to mothers in Mexico, suggesting that norms about children's body size may change due to migration to the US. It could be that exposure to US cultural norms regarding body image causes Mexican immigrant mothers in the US to prefer a smaller child body size compared to what they preferred in Mexico. Another migration-related hypothesis generated by this study was that immigrants may retain the cultural preference for larger child body type in the US to some extent. When stratified by child weight status, we found that US mothers of at-risk-for-overweight children chose larger ideal figures than they perceived their child to currently be. This may reflect the Mexican cultural norm toward larger ideal body types for children and show that vestiges of this cultural norm persist in Mexican immigrant communities in the US. 
The limitations of this study are important to consider. First, a small sample of mothers answered our questions in the California sample, $(n=60)$. However, there were no significant differences between the women who answered the supplemental questionnaire and those who did not. Similarly, this study focused on Mexican immigrant mothers in California and mothers in migrant sending communities in Mexico, and therefore findings may not be generalizable to other Hispanic sub-groups. Finally, although we attempted to recruit comparable samples on either side of the border, the samples differed according to characteristics such as maternal education and household food insecurity, which may have made comparisons difficult.

The results of this study showed that Mexican mothers residing both in the US and Mexico frequently underestimate their child's size. Additionally, this study showed that approximately one-third of the Mexican immigrant mothers in the US and one-half of mothers in Mexico wanted their children to be bigger than they currently perceived them to be. Thus, traditional health education models that motivate mothers to make changes in their children's diet and physical activity by discussing health consequences of overweight are not likely to be successful. Programs to address overweight among children of Mexican descent in both the US and Mexico may be more effective if they focus on alternative benefits of weight control strategies. For example, programs could promote good nutrition and physically active lifestyles for healthy child development as opposed to only for prevention or reduction of overweight.

Open Access This article is distributed under the terms of the Creative Commons Attribution Noncommercial License which permits any noncommercial use, distribution, and reproduction in any medium, provided the original author(s) and source are credited.

\section{References}

1. Ogden, C. L., Carroll, M. D., Curtin, L. R., McDowell, M. A., Tabak, C. J., \& Flegal, K. M. (2006). Prevalence of overweight and obesity in the United States, 1999-2004. Jama, 295(13), 1549-1555.

2. Ariza, A. J., Chen, E. H., Binns, H. J., \& Christoffel, K. K. (2004). Risk factors for overweight in five- to six-year-old Hispanic-American children: A pilot study. Journal of Urban Health, 81(1), 150-161.

3. Hackie, M., \& Bowles, C. L. (2007). Maternal perception of their overweight children. Public Health Nursing, 24(6), 538-546.

4. Rhee, K. E., De Lago, C. W., Arscott-Mills, T., Mehta, S. D., \& Davis, R. K. (2005). Factors associated with parental readiness to make changes for overweight children. Pediatrics, 116(1), e94-e101.

5. Crawford, P. B., Gosliner, W., Anderson, C., Strode, P., BecerraJones, Y., Samuels, S., et al. (2004). Counseling Latina mothers of preschool children about weight issues: Suggestions for a new framework. Journal of the American Dietetic Association, 104(3), 387-394.

6. Flegal, K. M., Ogden, C. L., \& Carroll, M. D. (2004). Prevalence and trends in overweight in Mexican-american adults and children. Nutrition Reviews, $62(7 \mathrm{Pt}$ 2), S144-S148.

7. Killion, L., Hughes, S. O., Wendt, J. C., Pease, D., \& Nicklas, T. A. (2006). Minority mothers' perceptions of children's body size. International Journal of Pediatric Obesity, 1(2), 96-102.

8. Brewis, A. (2003). Biocultural aspects of obesity in young Mexican schoolchildren. American Journal of Human Biology, $15,446-460$.

9. Dietz, W. H. (1994). Critical periods in childhood for the development of obesity. American Journal of Clinical Nutrition, 59(5), 955-959.

10. Dietz, W. H. (1997). Periods of risk in childhood for the development of adult obesity-what do we need to learn? Journal of Nutrition, 127(9), 1884S-1886S.

11. Adair, L. S. (2008). Child and adolescent obesity: Epidemiology and developmental perspectives. Physiology \& Behavior, 22; 94(1), 8-16.

12. Eskenazi, B., Gladstone, E. A., Berkowitz, G. S., Drew, C. H., Faustman, E. M., Holland, N. T., et al. (2005). Methodologic and logistic issues in conducting longitudinal birth cohort studies: Lessons learned from the centers for children's environmental health and disease prevention research. Environmental Health Perspectives, 113(10), 1419-1429.

13. INEGI. Conteo de poblacion y vivienda (2005). Population and housing census 2005. [cited 2008 July 1, 2008]. Available from, http://www.inegi.gob.mx/inegi/default.aspx?s=est\&c=10202.

14. National Center for Health Statistics (2005). CDC growth charts, United States.

15. Collins, M. (1991). Body figure perceptions and preferences among preadolescent children. International Journal of Eating Disorders, 10, 199-208.

16. Olvera, N., Suminski, R., \& Power, T. G. (2005). Intergenerational perceptions of body image in hispanics: Role of BMI, gender, and acculturation. Obesity Research, 13(11), 19701979.

17. Contento, I. R., Basch, C., \& Zybert, P. (2003). Body image, weight, and food choices of Latina women and their young children. Journal of Nutrition Education and Behavior, 35(5), 236-248.

18. Guendelman S, Fernald LC, Neufeld LM, Fuentes-Afflick E. (2009). Maternal perceptions of overweight in young Latino children in California and Mexico. Journal of the American Dietetic Association, in press.

19. WHO. (1995). Physical status: The use and interpretation of anthropometry. Geneva: World Health Organization.

20. Falkingham, J., \& Namazie, C. (2002). Measuring health and poverty: A review of approaches to identifying the poor. London: Department for International Development Health Systems Resource Centre.

21. Fernald, L. C. (2007). Socio-economic status and body mass index in low-income Mexican adults. Social Science and Medicine, 64(10), 2030-2042.

22. Vyas, S., \& Kumaranayake, L. (2006). Constructing socio-economic status indices: How to use principal components analysis. Health Policy Plan, 21(6), 459-468.

23. Arcia, E., Skinner, M., Bailey, D., \& Correa, V. (2001). Models of acculturation and health behaviors among Latino immigrants to the US. Social Science and Medicine, 53(1), 41-53.

24. Maximova, K., McGrath, J. J., Barnett, T., O'Loughlin, J., Paradis, G., \& Lambert, M. (2008). Do you see what I see? Weight status misperception and exposure to obesity among children and adolescents. International Journal of Obesity (London), 32(6), $1008-1015$. 
25. Peterson, M., Ellenberg, D., \& Crossan, S. (2003). Body-image perceptions: Reliability of a BMI-based Silhouette Matching Test. American Journal of Health Behaviour, 27(4), 355-363.

26. McIza, Z., Goedecke, J. H., Steyn, N. P., Charlton, K., Puoane, T., Meltzer, S., et al. (2005). Development and validation of instruments measuring body image and body weight dissatisfaction in South African mothers and their daughters. Public Health Nutrition, 8(5), 509-519.

27. Baughcum, A. E., Chamberlin, L. A., Deeks, C. M., Powers, S. W., \& Whitaker, R. C. (2000). Maternal perceptions of overweight preschool children. Pediatrics, 106(6), 1380-1386.

28. Maynard, L. M., Galuska, D. A., Blanck, H. M., \& Serdula, M. K. (2003). Maternal perceptions of weight status of children. Pediatrics, 111(5 Part 2), 1226-1231.

29. Etelson, D., Brand, D. A., Patrick, P. A., \& Shirali, A. (2003). Childhood obesity: Do parents recognize this health risk? Obesity Research, 11(11), 1362-1368.

30. Eckstein, K. C., Mikhail, L. M., Ariza, A. J., Thomson, J. S., Millard, S. C., \& Binns, H. J. (2006). Parents' perceptions of their child's weight and health. Pediatrics, 117(3), 681-690.
31. May, A. L., Donohue, M., Scanlon, K. S., Sherry, B., Dalenius, K., Faulkner, P., et al. (2007). Child-feeding strategies are associated with maternal concern about children becoming overweight, but not children's weight status. Journal of the American Dietetic Association, 107(7), 1167-1175.

32. Myers, S., \& Vargas, Z. (2000). Parental perceptions of the preschool obese child. Pediatric Nursing, 26(1), 23-30.

33. Brewis, A. (2003). Biocultural aspects of obesity in young Mexican schoolchildren. American Journal of Human Biology, 15(3), 446-460.

34. Fernald, L. C., \& Neufeld, L. M. (2007). Overweight with concurrent stunting in very young children from rural Mexico: Prevalence and associated factors. European Journal of Clinical Nutrition, 61(5), 623-632.

35. Rosas L, Harley K, Fernald LC, Guendelman S, Mejia F, Neufeld LM, et al. (2009). Dietary associations of household food insecurity among children of mexican descent: results of a binational study. Journal of the American Dietetic Association, in press. 